\title{
Full Penetration-Practical Research on Using Class Music Cloud Drive to Promote Music Appreciation Teaching Activities in Senior High School
}

\author{
Yan Bu \\ Xiaoshan High School, Gongxiu Road, Chengxiang Street, Xiaoshan District, Hangzhou 311200, China
}

\begin{abstract}
Under the background of advocating the combination of modern educational technology and educational teaching. This research takes artistic accomplishment as the guidance, creates a class wide music cloud platform. Integrates modern information technology into multiple dimensions of music teaching and strives to create a high-quality modern music appreciation course. This paper illustrates the summarization of the application of modern educational technology into the class wide music cloud platform from three perspectives before, during and after class, combining with teaching practice, and puts forward a scheme to make it normalized.
\end{abstract}

Keywords: Modern educational technology, Class wide music cloud platform, Music appreciation.

\section{Situational Analysis of Research Problems}

Using modern educational technology to help achieve a better class is an inevitable trend of development these days, especially for the discipline of music. The school where the author works cooperate with iFLYTEK Co. Ltd. to carry out the project of "smart campus informatization", create a class music cloud drive, make full use of network resources and modern technology to solve the existing problems in the music class, and guide students to learn effectively, which is what teachers always need to think about.

\subsection{Reflective Behavior Based on The Current Situation}

(1) Students lack the awareness of independent perception: specifically, students are used to relying on the guidance of teachers when they listen to music, lacking the ability to feel music actively, and have emotional resonance rarely;

(2) Students cannot express their feelings about music works accurately: in the appreciation activities of music works in senior high school, students often don't know how to describe their feelings and can only give some simple emotional words, such as "joy" and "sadness";

(3) Students will not express and create actively: students are in a state of passive learning. Most of them can not really participate, let alone express and create by physical or other means.

\subsection{Find the Cause Based on the Problem}

(1) Music itself is relatively abstract. Most students' music foundation is relatively weak. Students' understanding is not enough only by listening to music and teachers' explanation.

(2) Teachers lack the awareness of students as the main body of the class. Teachers talk too much in a class and the teaching means are single. They do not make full use of various scientific and technological information means to assist students in music understanding and music imagination, so as to put students in a state of passive learning.
(3) The use of educational information technology means is single. Many teachers only use educational technology as a situational creation or teaching tool, which can not let the music enter students' hearts at all.

In view of the above problems, the author believes that modern educational technology plays a very key role in stimulating students' learning enthusiasm, providing technical support for the development of music class activities, broadening and improving the evaluation mechanism. How to use educational information technology to understand the basis and needs of students before teaching, create a better music class in teaching, obtain teaching feedback after teaching, and guide students to learn effectively is of great value.

\section{Operational Definition of Core Concepts}

Class music cloud drive: it refers to the use of learning tablets shared by teachers and students to create a class music platform for the design, development, utilization, management, and evaluation of resources, so as to achieve teaching optimization.

Music Appreciation: in this topic, music appreciation mainly refers to the appreciation part of high school music class. High school music curriculum standard divides the course into six modules, and music appreciation is the required course with the largest proportion.

Full penetration: in this topic, full penetration refers to the use of class music cloud drive to penetrate through the whole process of music appreciation activities through means, content, and emotion.

\section{Research Direction, Content and Process}

\subsection{Research Objectives}

This topic hopes to create a class music cloud drive with the help of modern information technology, use information technology to optimize music appreciation activities before, 
during, and after teaching. And further, promote the use of modern information technology in high school music class.

\subsection{Research Principles}

(1) Student subject principle: always take students as the subject of research and make class requirements to varying degrees according to students' music foundation. As an auxiliary means, modern educational technology is based on the principle of how to better understand and express works for students of different levels.

(2) Teaching principle for music: the content of music appreciation is very rich. In the design and organization of each teaching activity, we should take the works of the above courses as the material, appropriately use modern educational technology and comprehensively use different teaching means according to the basis of students and teaching objectives, so as to achieve the effect of each content.

(3) Principle of operability: according to the characteristics of music appreciation teaching, it is easy to operate and promote by using simple and clear modern information technology such as tablets and resource databases.

\subsection{Research Content}

In this study, students are taken as the research subject to establish a class music cloud drive. According to the music appreciation content and students' music foundation, modern educational technology is appropriately used and different teaching methods are comprehensively used to achieve the effect of each content. The specific operation methods are shown in Figure 1.

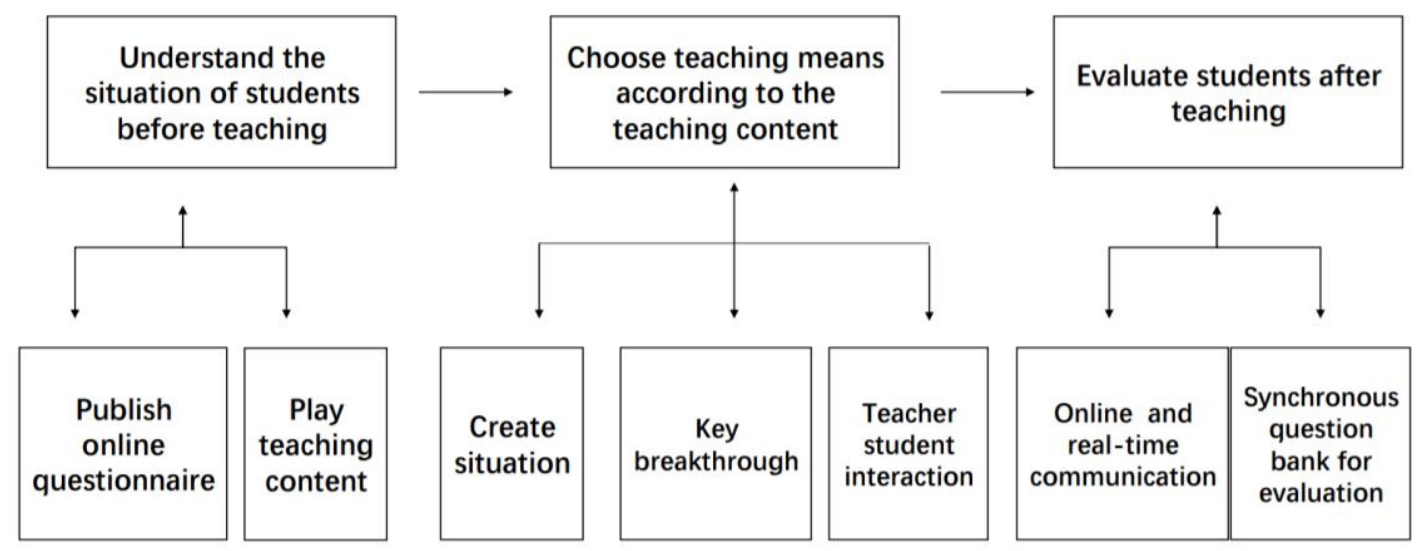

Figure 1: General structure of research content

(1) Application of modern educational technology before teaching:

Understand students' music knowledge base and music literacy. Through the online questionnaire or music knowledge quiz sent by the tablet shared by teachers and students, we can grasp the basic situation of students to face and have better preset and overall control over the class.

Using the class cloud drive to create a resource library, students can find the materials they need in the resource library at any time, and play the works explained in class in advance, which will have a better auxiliary effect on the class, let students enter the learning state in advance, have a preliminary study of the works, understand the background of the works and have an independent feeling of the works. Students can also use the tablet to write down their understanding of the works in the course discussion area, which is convenient for teachers to understand students' preliminary perception of the works.

(2) Application of modern educational technology in Teaching:

In the process of teaching, use the tablet for real-time interaction, depict melody lines, rush to answer in class, stimulate students' interest in learning and desire for knowledge, and mobilize the whole class atmosphere.
In the process of teaching, use the tablet to realize the interaction between teachers and students as much as possible. Interaction plays an important role in narrowing the distance between teachers and students and adjusting the class atmosphere. Teachers use modern educational technology to create more interactive links between teachers and students. Reduce the trough of students' attention and improve learning efficiency.

In the process of teaching, the use of tablets can also help the class broaden the way of artistic expression. The appreciation class can not just stay in the appreciation itself. The cultivation of singing, performance, music editing, and creation needs to be implemented in each class. Many times, due to various restrictions, the traditional music class can not carry out a variety of artistic activities. With the help of modern educational technology, it is found that these obstacles to the artistic activities in the traditional class can be resolved.

(3) Application of modern educational technology after teaching:

When making a summary in the class using the tablet can allow students to feedback the knowledge learned in the class, set the problems in the class space, and feedback to the class in time, rather than end at the end of the class. It is also a very important part for teachers to understand the degree of students' absorption of class knowledge. 
After class, use the tablet to communicate with the teacher in time after class and give feedback on problems, which plays a good role in consolidating knowledge and continuous knowledge learning for the next class. Use modern educational technology to evaluate teaching, constantly improve, enrich the class and improve teaching.

Modern educational technology can help teachers evaluate students after class. Modern educational technology can realize machine-assisted evaluation. Teachers can publish small exercises in the form of objective questions on the Internet. The software will correct the answers entered by teachers in advance and present the answers of students. The machine can also help judge the singing part, and the scoring machine will score the students' singing. The subjective questions can be graded by students. Teacher evaluation is the most important part. It evaluates the whole process of the course and summarizes the evaluations of all parties to form an evaluation record form for archiving and feedback to students.

\section{Conclusion}

The national information technology education conference stressed: "emphasize information technology education resources, promote the promotion of information technology means in the teaching practice of other disciplines, combine the teaching of other disciplines with information technology education, build good environmental conditions, and promote the sustainable development of modern information technology." In the 21 st century, under the school education and teaching reform, we advocate "The combination of modern information technology and curriculum", information technology will be the center of educational technology, and modern educational technology will become an integral part of teaching, which will inevitably become a new development trend.

The combination of modern educational technology and music discipline has caused profound changes in teaching, changed the traditional teaching model, and caused changes in learning methods and evaluation means. The integration of modern information technology elements in music teaching is of great significance to accelerate educational modernization, improve students' aesthetic ability, and change music learning methods. This is a long lesson and needs to be learned Teachers should work together.

\section{References}

[1] Li Yang. Research on the application of modern educational technology in the teaching of new music curriculum in Senior High School[D] Central China Normal University, 2008.

[2] Tao Xu. Discussion on multimedia music teaching[J]. Science and Technology Consulting Guide, 2007(27).

[3] Meiye Chen. The implementation strategy of the effectiveness of music classroom teaching[J]. New Curriculum Learning (Comprehensive) 2010(08).

[4] Weiping Chen. Application of modern educational technology in music teaching[J] China's Educational Technology Equipment, 2011, (25). 